\title{
Speakers' assumptions about the lexical flexibility of idioms
}

\author{
RAYMOND W. GIBBS, JR., NANDINI P. NAYAK, \\ JOHN L. BOLTON, and MELISSA E. KEPPEL \\ University of California, Santa Cruz, Santa Cruz, California
}

\begin{abstract}
In three experiments, we examined why some idioms can be lexically altered and still retain their figurative meanings (e.g., John buttoned his lips about Mary can be changed into John fastened his lips about Mary and still mean "John didn't say anything about Mary"), whereas other idioms cannot be lexically altered without losing their figurative meanings (e.g., John kicked the bucket, meaning "John died," loses its idiomatic meaning when changed into John kicked the pail). Our hypothesis was that the lexical flexibility of idioms is determined by speakers' assumptions about the ways in which parts of idioms contribute to their figurative interpretations as a whole. The results of the three experiments indicated that idioms whose individual semantic components contribute to their overall figurative meanings (e.g., go out on a limb) were judged as less disrupted by changes in their lexical items (e.g., go out on a branch) than were nondecomposable idioms (e.g., kick the bucket) when their individual words were altered (e.g., punt the pail). These findings lend support to the idea that both the syntactic productivity and the lexical makeup of idioms are matters of degree, depending on the idioms' compositional properties. This conclusion suggests that idioms do not form a unique class of linguistic items, but share many of the properties of more literal language.
\end{abstract}

Idiomatic phrases in English differ in the degree to which their lexical items can be changed and still maintain their figurative meanings. For example, the word button in the idiomatic phrase button your lip (meaning "don't say anything"') can be changed to fasten your lips without disrupting the figurative meaning of the expression. Similarly, the phrase eat one's words can have its verb changed without disrupting its overall figurative interpretation (i.e., swallow one's words). Idioms such as button your lips and eat one's words seem to be lexically flexible, in that their individual components can be altered without significant damage to their nonliteral meanings. Other idiomatic phrases seem to be lexically frozen, in that changing any of their individual components severely disrupts their figurative meanings. For instance, speakers can say kick the bucket to mean "die," but they cannot say kick the pail or even punt the bucket without losing the idiomatic sense of the expression.

Our purpose in this paper is to present evidence in support of a hypothesis explaining exactly why some idioms are lexically flexible and others are not. We suggest that the lexical flexibility of idioms is not an arbitrary phenomenon, but depends specifically on how the internal semantics of these phrases relate to their overall figurative interpretations.

This research was supported by a faculty research grant from the University of California, Santa Cruz. We wish to thank Rachel Mueller for her valuable comments on an earlier draft of this paper. Reprint requests may be sent to Raymond W. Gibbs, Jr., Program in Experimental Psychology, Clark Kerr Hall, University of California, Santa Cruz, CA 95064
Linguistic theories have traditionally assumed that idioms are noncompositional, that is, that the meaning of an idiom is not a function of the meaning of its parts (Chomsky, 1980; Fraser, 1970; Heringer, 1976; Katz, 1973). Thus, the nonliteral meaning of the well-known phrase kick the bucket (i.e., "die") cannot be determined through an analysis of the individual words' meanings. One implication of this view has been that the figurative meanings of idiomatic phrases must be directly stipulated in the mental lexicon in the same way that the meanings of individual words are listed in a dictionary. Various computational models of natural language processing have even postulated a "phrasal lexicon" containing common formulaic and idiomatic phrases that can easily be retrieved during comprehension (Becker, 1975; Gasser \& Dyer, 1986; Wilensky \& Arens, 1980).

There are significant difficulties with the view that idioms are noncompositional. One problem concerns the syntactic productivity of idioms, that is, how idioms differ in the extent to which they can be syntactically altered and still maintain their figurative meanings. Thus, some idioms, such as John laid down the law (meaning "John enforced the rules") are syntactically productive, because they can be put into the passive voice without losing their figurative interpretations (The law was laid down by John). Other idioms, such as John kicked the bucket (meaning "John died"), are not perceived as idiomatic when they are syntactically changed (The bucket was kicked by John). It is difficult to imagine a view that could account for differences in the syntactic productivity of idioms and yet maintain that all idioms are noncompositional. 
Another problem for the view that idioms are noncompositional comes from the observation, noted above, that idioms differ in their degree of lexical flexibility. One could argue that each form of a lexically flexible idiom (e.g., button your lips, fasten yours lips) is represented as a separate entry in a phrasal lexicon (Weinreich, 1969). However, this possibility alone would not account for why some idioms are inherently more flexible than others in their lexical makeup. Our thesis is that differences in the lexical flexibility of idioms can be explained in much the same way as differences in the syntactic productivity of idioms.

In earlier work, Gibbs and Nayak (in press) examined the idea that the syntactic behavior of idioms is determined by the internal semantics of these figurative phrases. This proposal, called the idiom decomposition hypothesis, states that speakers make assumptions about the way in which parts of idioms contribute to their figurative interpretations as wholes. Speakers' intuitions of the syntactic versatility of idioms should be affected by their assumptions regarding the analyzability or decomposability of these figurative phrases.

The idiom decomposition hypothesis, then, suggests that idioms differ in the degree to which these phrases' individual components contribute to their overall figurative meanings. To test the idea that the syntactic behavior of idioms is determined by their degree of semantic decomposition, Gibbs and Nayak (in press) conducted a series of experiments in which subjects were presented with idiomatic phrases, in different syntactic constructions, along with paraphrases of their figurative meanings (e.g., The bucket was kicked by John; John died). The subjects' task was to judge the similarity of meaning of the two sentences.

Gibbs and Nayak (in press) presented three different types of idiomatic phrases to their subjects. In "normally decomposable" idioms, each of the components referred in some way to its idiomatic referent. Thus, in the phrase pop the question, it is easy to discern that the noun question refers to a marriage proposal when the verb pop is used to refer to the act of uttering it. Similarly, law in lay down the law refers to rules of conduct when the verb phrase lay down is used to refer to the act of invoking the law. It is easy to see how each of the components of a normally decomposable idiom contributes to the idiom's holistic interpretation, and we normally assume that other speakers will break down these idioms as we do. Idioms whose individual parts do not contribute individually to the figurative meaning of the idiom are semantically "nondecomposable"' (e.g., kick the bucket, chew the fat) and we generally assume that other speakers will experience difficulty in breaking these phrases into their component parts.

In some decomposable idioms, however, the relationship between the individual components and their idiomatic referents is different. For example, we cart identify the figurative referent in the idiom carry $a$ torch only by virtue of our knowledge that the torch is a conventional metaphor for warm feelings. These "abnormally decomposable" idioms should not be syntactically productive, because each individual part refers not to the idiomatic referent, but only to some metaphorical relationship between the individual part and the referent.

Gibbs and Nayak's (in press) results indicated that the more decomposable an idiom was, the more likely it was that the idiom would be syntactically productive. Normally decomposable idioms (e.g., pop the question) were found to be much more syntactically productive than either abnormally decomposable (e.g., carry a torch) or semantically nondecomposable (e.g., chew the fat) idioms. These findings generally support the predictions of the idiom decomposition hypothesis, and suggest that the syntactic behavior of idioms can be explained through examination of their internal semantics.

Our goal in the present study was to show that the same principle that motivates differences in the syntactic behavior of idioms can also explain why some idioms are lexically flexible and others are not. If the individual parts of semantically decomposable idioms contribute separately to these phrases' overall figurative meanings, then changing any one of these parts by inserting a synonym in its place should not be as disruptive to their figurative interpretations as would substituting synonyms for parts of nondecomposable idioms. If the individual parts of an idiom do not systematically contribute to its figurative meaning, as in the case of a semantically nondecomposable idiom, then changing these parts in any way would severely alter this idiom's overall figurative interpretation.

In each of the experiments described here, we tested the idea that the lexical flexibility of idioms depends on their internal semantics. These experiments assessed people's intuitions about the lexical composition of idioms in English. The subjects were asked to judge the similarity between sentences containing idioms that were lexically changed and sentences that contained paraphrases of the figurative interpretations of the original idioms. We did not expect the subjects to view the changed idioms as being equal in quality to their unchanged, original forms. Rather, the subjects' ratings should reflect how much any lexical change disrupted the nonliteral meaning of different kinds of idioms.

The purpose of Experiment $1 \mathrm{~A}$ was to determine whether people can distinguish between normally decomposable, abnormally decomposable, and semantically nondecomposable idioms apart from consideration of their lexical flexibility. In Experiment 1B we investigated whether people view normally decomposable idioms as being more lexically flexible-that is, more capable of being lexically changed through the substitution of one word for another-than abnormally decomposable or semantically nondecomposable idioms. In Experiment 2 we tested the alternative hypothesis that the lexical makeup of idioms depends on their literal well-formedness. In Experiment 3 we examined the relationship between lexical flexibility 
and syntactic productivity. In the General Discussion, we evaluate the implications of our results for theories of idiomaticity and for the "on-line" processing of idioms.

\section{EXPERIMENT 1A}

Our goal in the first experiment was to validate our claim that idioms differ in their degree of semantic decomposition. The subjects were presented with a series of idioms and were asked to decide whether the individual words in each expression made some unique contribution to the phrase's nonliteral interpretations. Our expectation was that the subjects would consistently categorize each idiom as belonging to one of three categories: semantically decomposable, abnormally decomposable, or semantically nondecomposable.

\section{Method}

Subjects. Twenty-four undergraduates from the University of California, Santa Cruz, participated as subjects to fulfill a course requirement. All of the subjects in this and the following experiments were native English speakers.

Stimuli, Design, and Procedure. From the study by Boatner, Gates, and Makkai (1975), we selected 40 idioms consisting of a verb phrase plus a noun phrase $(\mathrm{V}+\mathrm{NP})$. We chose these idioms to include at least 12 normally decomposable idioms, 12 abnor mally decomposable idioms, and 12 semantically nondecomposable phrases based on our own intuitions. Each idiom was paired with a paraphrase of its figurative meaning, also taken from Boatner et al. (e.g., weigh your words, choose what you say carefully; waste your breath, speak without results; hit the hay, go to bed; go jump in a lake, quit being a bother; ring a bell, recall something familiar).

The subjects were given a booklet containing a written set of instructions and the 40 idiom-paraphrase pairs. They were instructed to judge whether the individual components of each idiom made some unique contribution to the phrase's figurative meaning. The subjects were asked initially to group the idioms into two categories idioms whose individual components contributed to their overall figurative meanings (decomposable) and idioms whose individual components did not make such a contribution (nondecomposable). Then they were to divide the decomposable idioms into two groups: idioms whose individual components had a literal relationship to their figurative referents and idioms whose individual components had some metaphorical relationship to their idiomatic referents.

The instructions to subjects were:

Some decomposable idioms have words whose meanings directly relate to their figurative interpretations. For example, the phrase pop the question has two words which are closely related to their individual figurative meanings. Thus, the word pop is closely related to the idea of "suddenly asking" or "suddenly proposing" while the word question refers to a particular kind of question, namely a "marriage proposal." Idiom phrases like this are called "normally decomposable." On the other hand, there are idioms that are decomposable but whose individual words have a more metaphorical relation to their figurative meanings. Thus, the phrase spill the beans means something like "reveal a secret." Although there is a fairly close relationship between spill and "reveal, " the word beans refers to "secrets" in a less direct, metaphorical way. Idioms such as spill the beans are called "abnormally decomposable."

The instructions made no mention of the possibility that the idioms might differ in their degree of lexical flexibility or their syntactic productivity. After the subjects had classified the decomposable idioms as "normal" or "abnormal," some individuals were ques tioned as to whether they noticed any other dimension along which the idioms differed. None of the subjects asked suggested that some idioms might be lexically flexible and others not.

\section{Results and Discussion}

The proportion of subjects categorizing each idiom as being normally decomposable, abnormally decomposable, or semantically nondecomposable was calculated. With the exception of three idioms, each idiomatic phrase was seen as being a member of one category at least $75 \%$ of the time. The mean proportion of agreement was $86 \%$ for normally decomposable idioms, $79 \%$ for abnormally decomposable idioms, and $88 \%$ for semantically nondecomposable idioms. Each of these proportions was statistically different from chance $(p<.05)$ according to one-tailed binomial tests (with a null hypothesis probability of .50).

These data show that idioms differ in their degree of semantic decomposition and that subjects can agree on the classification of any individual expression. Again, it is important to emphasize that individual subjects made their decisions about the semantic decomposition of idioms without awareness of the lexical flexibility of these phrases. From the group of 37 categorizable idioms we randomly discarded one phrase, leaving 12 idioms viewed as normally decomposable, 12 as abnormally decomposable, and 12 as nondecomposable. The 12 idioms in each group are presented in Appendix A.

\section{EXPERIMENT 1B}

The purpose of Experiment 1B was to directly test the possibility that semantically decomposable idioms are more lexically flexible than nondecomposable idioms. Decomposable idioms should be lexically flexible if the substitutions refer to the same states or activities as the original lexical items. Thus, people should find burst the ice (for break the ice) more related in meaning to "start up a conversation" than boot the bucket (for kick the bucket) is to "die." Our expectation was that the subjects would give higher ratings to semantically decomposable idioms with different word changes than they would to nondecomposable idioms with similar lexical changes. Such a finding would indicate that people perceive semantically decomposable idioms as having greater lexical flexibility because these idioms contain individual lexical items that contribute to their overall idiomatic meanings.

\section{Method}

Subjects. Thirty-six undergraduate students from the University of California, Santa Cruz, served as subjects to fulfill a course requirement. None of these subjects had participated in Experiment $1 \mathrm{~A}$.

Stimuli and Design. The 12 normally decomposable, 12 abnormally decomposable, and 12 nondecomposable idioms from Experiment $1 \mathrm{~A}$ were used as stimuli. There are no measures of frequency for idioms such as there are for individual words (cf. Carroll, Davies, \& Richman, 1976; Kucera \& Francis, 1967); therefore, we assessed the familiarity of these stimuli in a separate rating study in which 16 undergraduate students were presented with a ran- 
domized list of all the idioms and were asked to check each one that was familiar as a figurative expression. Overall, these subjects were familiar with $95 \%$ of the idioms, and an analysis of variance revealed no significant differences in the students' familiarity with the three types of idioms.

Each of the 36 idioms either was left unchanged or was altered by substituting a lexical item with a similar meaning for the noun, the verb, or both. The word to be changed was looked up in a thesaurus and all of its synonyms were examined; then the synonym was chosen that best maintained the overall figurative meaning of the idiom and was closest in meaning to the original word. We purposely restricted the substitutions to synonyms to maintain some degree of control over the lexical changes. The new words for each idiom did not differ statistically from the original words in terms of their overall frequency as determined by the ratings from Carroll et al. (1976).

Each idiom (in either its unchanged or changed form) was paired with a paraphrase of the unchanged idiom's meaning. These paraphrases came directly from Boatner et al. (1975) and were identical to those used in Experiment 1A. Four sets of materials were formed from the 36 idioms. Each set contained 12 normally decomposable, 12 abnormally decomposable, and 12 nondecomposable idioms. In each set, 9 idioms had no changes, 9 had verb changes, 9 had noun changes, and 9 had both verb and noun changes. The different sets were appropriately counterbalanced so that an idiom presented with no changes in Set $A$ was shown with a verb change in Set $B$, a noun change in Set $C$, and both changes in Set $D$. Table 1 presents examples of the three types of idioms in each of their changed forms.

Procedure. The subjects received a booklet containing 36 stimulus items. The subjects' task was to read each expression and rate on a scale of 1 to 7 the degree to which the paraphrase characterized the meaning of the expression (with 1 indicating not at all similar in meaning and 7 indicating highly similar in meaning). This task assumes that subjects' ratings reflect the degree to which an idiom can be lexically altered and still maintain its figurative meaning The instructions emphasized that subjects should make these similarity judgments according to the way each phrase was actually presented. The task took approximately $15 \mathrm{~min}$ to complete

\section{Results and Discussion}

The mean ratings are shown in Table 2 . High numerical ratings indicate that the subjects viewed a particular lexical change as maintaining the idiomatic interpretation; low ratings indicate that an idiom in some changed form did not retain its idiomatic meaning. The average standard error for these ratings was \pm .28 .

Each analysis was performed twice, once treating subjects as a random factor while collapsing across sentences $(F 1)$ and once treating sentences as a random factor while collapsing over subjects $(F 2)$. Min $F^{\prime}$ was also calculated. as recommended by Clark (1973). We have placed greatest reliance on effects that were significant by $\min F^{\prime}$, but results that achieved significance by subjects and items should also be seriously considered.

An analysis of variance on these data revealed significant main effects of idiom type $[F 1(2,60)=8.1$, $p<.001 ; F 2(2,33)=4.2, p<.025 ; \min F^{\prime}(2,66)=$ $2.8, p<.10]$ and substitution $[F(3,90)=33.9$. $p<.001 ; F 2(3,99)=25.7, p<.001 ; \min F^{\prime}(3,187)=$ 14.6, $p<.001]$. The interaction between these two variables was not statistically significant $[F 1(6,180)=0.9$. $p>.10 ; F 2(6,99)=1.7, p>.101$.

The lack of an interaction between idiom type and substitution was surprising. Our original hypothesis predicted that the subjects' ratings would not vary as a function of idiom type when no lexical change was made, but should be less affected by lexical changes when the idioms were semantically decomposable. Closer examination of the ratings for each type of idiom indicated much greater variability in the subjects' judgments about the lexical flexibility of abnormally decomposable idioms $(S E= \pm .38)$ than in judgments about either normally decomposable $(S E= \pm .23)$ or semantically nondecomposable $(S E=$ $\pm .24)$ phrases. The greater variation in the ratings for abnormally decomposable idioms is most likely due to people's differing intuitions about whether a given idiomatic phrase is normally or abnormally decomposable. The data from Experiment 1A showed that there was less agreement as to whether an idiom was normally or abnormally decomposable than there was as to whether an

Table 1

Examples of Stimuli Used in Experiment 1B

\begin{tabular}{|c|c|c|c|}
\hline \multirow[b]{2}{*}{ Lexical Change } & \multicolumn{3}{|c|}{ Idiom Type } \\
\hline & $\begin{array}{c}\text { Normally } \\
\text { Decomposable }\end{array}$ & $\begin{array}{c}\text { Abnormally } \\
\text { Decomposable }\end{array}$ & Nondecomposable \\
\hline $\begin{array}{l}\text { None } \\
\text { Verb } \\
\text { Noun } \\
\text { Both }\end{array}$ & $\begin{array}{l}\text { pop the question } \\
\text { burst the question } \\
\text { pop the question } \\
\text { burst the request }\end{array}$ & $\begin{array}{l}\text { carry a torch } \\
\text { hold a torch } \\
\text { carry a light } \\
\text { hold a light }\end{array}$ & $\begin{array}{l}\text { kick the bucket } \\
\text { punt the bucket } \\
\text { kick the pail } \\
\text { punt the pail }\end{array}$ \\
\hline
\end{tabular}

Table 2

Mean Similarity Ratings, Experiment 1B

\begin{tabular}{|c|c|c|c|c|}
\hline \multirow[b]{2}{*}{ Lexical Change } & \multicolumn{3}{|c|}{ Idiom Type } & \multirow[b]{2}{*}{ Mean Rating } \\
\hline & $\begin{array}{c}\text { Normally } \\
\text { Decomposable }\end{array}$ & $\begin{array}{c}\text { Abnormally } \\
\text { Decomposable }\end{array}$ & Nondecomposable & \\
\hline None & 5.44 & 5.42 & 5.35 & 5.38 \\
\hline Verb & 3.52 & 3.61 & 3.21 & 3.46 \\
\hline Noun & 4. 10 & 3.67 & 3.20 & 3.69 \\
\hline Both & 3.23 & 3.10 & 2.50 & 2.94 \\
\hline Mean Rating & 4.08 & 3.95 & 3.58 & \\
\hline
\end{tabular}


idiom was decomposable or nondecomposable. Thus, the lack of an interaction between idiom type and substitution could be due to idiosyncracies in the group of abnormally decomposable items. When the relationship of idiom type and substitution was tested with the data for the abnormally decomposable idioms excluded, there was a statistically significant interaction in the analysis over subjects $[F 1(3,90)=2.8, p<.05]$ and a marginally reliable interaction in the analysis over items $[F 2(3,36)=$ $2.3, p<.10$ ]. This partially demonstrates that people's ratings of normally decomposable and nondecomposable idioms do not vary when these idioms are not lexically changed, but do vary when their individual lexical items are altered.

The presence of an idiom type $\times$ substitution interaction permitted further examination of the group means, using Newman-Keuls tests. This analysis showed that subjects gave higher ratings to the unchanged idioms than to any of the changed idioms $(p<.01$ across both subjects and items for all comparisons). The difference between the verb-change and noun-change idioms was not reliable, but the verb- and noun-change idioms each differed significantly from the idioms in which both were changed $(p<.01$ across subjects and items for both comparisons).

Additional analysis on the individual means indicated that there were significant differences between the normally decomposable and nondecomposable idioms for each type of lexical change $(p<.05$ across subjects and items for all three comparisons). The abnormally decomposable idioms received higher ratings than did the nondecomposable idioms for each type of change $(p<.05$ across subjects and $p<.10$ across items for each comparison). Finally, the differences between the normally and abnormally decomposable idioms were reliable only for the noun change ( $p<.05$ across subjects, $p<.10$ across items).

These findings suggest that the lexical flexibility of idioms is due to their semantic composition. Idiomatic phrases that are normally decomposable are much more flexible in their lexical makeup than are nondecomposable idioms. Interestingly, the metaphorically decomposable idioms, which are not generally syntactically versatile, are also more lexically flexible than are nondecomposable idioms. It appears that as long as the lexical substitutions maintain the metaphorical relationship between an individual component in an idiom and its realworld referent, then people find the lexical change(s) less disruptive than lexical changes in nondecomposable idioms. Once again, this finding makes sense, given that the individual components of metaphorically decomposable idioms contribute separately to the idiom's overall figurative meanings.

\section{EXPERIMENT 2}

Another way in which idioms differ is in terms of their literal well-formedness. Some idiomatic phrases are liter- ally well-formed (e.g., hit the books, ring a bell), whereas other expressions are literally ill-formed (e.g., crack a joke, swallow one's pride). Mueller and Gibbs (1987) demonstrated that people process well-formed idioms faster than ill-formed idioms. These results suggest that these different types of idioms may be represented differentially in the mental lexicon. Literally well-formed idioms may receive their meanings according to the rules of semantic composition that combine the meanings of the parts into well-formed syntactic constituents. These same rules would not be applied to expressions that do not conform to the normal syntactic rules of the language (Dowty, Wall, \& Peters, 1980). Expressions that do not possess well-defined literal meanings (e.g., crack a joke) must receive their interpretations by stipulation in the lexicon.

These observations suggest the possibility that the lexical flexibility of idioms may be due not only to their degree of decomposability, but to their literal wellformedness as well. Literally well-formed idioms may be more lexically flexible than literally ill-formed idioms simply because ill-formed idioms receive their figurative meanings by stipulation, perhaps through the application of some meaning postulate. Changing the lexical makeup of literally well-formed idioms may be more acceptable because the normal rules of semantic composition apply. If this is true, then ill-formed idioms should be much less lexically flexible than well-formed idioms.

The purpose of Experiment 2 was to directly investigate these predictions. The subjects were asked to judge whether literally well-formed and ill-formed idioms maintained their figurative interpretations when lexically altered. If the subjects perceived only literally well-formed idioms as being lexically flexible, this would provide a strong alternative to the idea that the lexical flexibility of idioms can be best attributed to their degree of semantic decomposition.

\section{Method}

Subjects. The 54 subjects were from the same population as those used in Experiments $1 \mathrm{~A}$ and 1B.

Stimuli and Design. Three of the authors independently examined a list of 60 idioms taken from Boatner et al. (1975) and classified each expression as being literally well-formed or literally ill-formed. It was assumed that literally well-formed expressions did not violate any selectional restriction rules, whereas ill-formed expressions did violate such rules (Chomsky, 1965; Kempson, 1977). From this list, the judges unanimously agreed upon 20 idioms of each type. These idioms were then submitted to a separate group of 16 subjects, who categorized each expression as literally well-formed, literally ill-formed, or anomalous (see also Mueller \& Gibbs, 1987). Lexical flexibility of idioms was not mentioned to the subjects, and none seemed to note this factor when questioned during the debriefing. The subjects were in agreement $92 \%$ of the time on well-formed idioms and $88 \%$ of the time on ill-formed idioms. A complete list of the two types of idioms is presented in Appendix B.

Each idiomatic phrase was then left unchanged or changed in one of three ways: (1) a synonym was substituted for the main verb, (2) a synonym was substituted for the main noun, or (3) synonyms were substituted for both the main verb and the main noun. The new words did not differ statistically from the originals in terms of their overall frequency, as determined by Carroll et al.'s (1976) 
Table 3

Mean Similarity Ratings, Experiment 2

\begin{tabular}{lccc} 
& \multicolumn{2}{c}{ Idiom Type } & \\
\cline { 2 - 3 } Lexical Change & Well-Formed & Ill-Formed & Mean Rating \\
\hline None & 6.18 & 6.24 & 6.22 \\
Verb & 4.57 & 4.59 & 4.58 \\
Noun & 4.35 & 4.67 & 4.51 \\
Both & 3.57 & 3.56 & 3.57 \\
Mean Rating & 4.66 & 4.76 & \\
\hline
\end{tabular}

ratings. Each phrase was placed in an appropriate sentential context and paired with a sentence containing a paraphrase of its idiomatic meaning. Four sets of materials were formed from the 40 idioms; each set contained 20 literally well-formed and 20 literally ill-formed idioms. In each set of idioms, 5 had no changes, 5 had verb changes, 5 had noun changes, and 5 had both verb and noun changes. The different sets were appropriately counterbalanced in the same way as described for Experiment lB.

Procedure. The procedure was identical to that used in Experiment $1 \mathrm{~B}$.

\section{Results}

The mean ratings for each type of idiom in each of its changed forms are presented in Table 3 . The average standard error for these ratings was \pm .24 .

An analysis of variance on these ratings showed a highly significant main effect of lexical change $[F 1(3,159)=$ $136.7, p<.001 ; F 2(3,114)=64.0, p<.001$; $\left.\min F^{\prime}(3,266)=43.6, p<.001\right]$. The main effect of idiom type did not approach significance $[F 1(1,53)=1.9$, $p>.10 ; F 2(1,38)=0.2, p>.10]$, nor did the interaction of lexical change and idiom type $[F 1(3,159)=1.1$, $p>.10 ; F 2(3,114)=0.7, p>.10]$.

Individual comparisons on the group means showed that subjects gave higher ratings to unchanged idioms than to any of the changed idioms $(p<.01$ across subjects and items for all comparisons). Although the differences in ratings between verb- and noun-change idioms were not significant, both had higher ratings than did idioms with both changes ( $p<.05$ across subjects and items for both comparisons). These findings indicate that people do not see literally well-formed idioms as more lexically flexible than ill-formed idioms, and thus rule out the alternative hypothesis that the lexical flexibility of idioms can best be explained in terms of these phrases' literal wellformedness.

\section{EXPERIMENT 3}

The finding that the syntactic productivity of idioms depends on their semantic compositions (Gibbs \& Nayak, 1987) implies that there should be some relationship between syntactic productivity and lexical flexibility. If syntactically productive idioms are semantically decomposable, with the individual semantic components contributing to the idioms' overall figurative meanings, then changing one of these components should not be as disruptive as changing the individual components of frozen idioms. Because the lexical items in syntactically frozen idioms do not contribute to these idioms' figurative mean- ings, changing any of the words in frozen idioms should be relatively disruptive. The purpose of Experiment 3 was to investigate the possibility that syntactically productive idioms are more flexible in their lexical makeup than are syntactically frozen idioms.

The subjects were presented with a series of syntactically productive and frozen idioms in short sentence contexts and were asked to judge how similar each sentence was to a sentence containing a paraphrase of the original idiom's figurative meaning. Sometimes the original idiom was presented unchanged (e.g., kick the bucket), and other times a synonym replaced the verb (e.g., punt the bucket), the noun (e.g., kick the pail), or both (e.g., punt the pail).

Our hypothesis was that syntactically productive idioms are more flexible in their lexical makeup than syntactically frozen idioms. Consequently, we expected subjects to give higher similarity ratings to syntactically productive idioms with changed lexical items than to frozen idioms that had undergone similar changes. We predicted that subjects would give higher ratings to original idioms and progressively lower ratings to idioms in which the verb, noun, or both had been changed. There should, however, be some evidence of an idiom type $\times$ change type interaction, because subjects should give differentially lower ratings to the various changes, depending on the type of idiom.

\section{Method}

Subjects. The 36 subjects were from the same population as those used in the previous experiments. None of the subjects had participated in any of the earlier experiments.

Stimuli and Design. Sixty V + NP idioms selected from Boatner et al. (1975) were rated by three of the authors as to whether these idioms maintained their figurative interpretations when syntactically transformed. Each expression was transformed in six ways (action nominalized, adverb inserted, verb changed to present participle, voice changed to passive, particle moved, adjective inserted). Syntactically frozen idions were those that could not be transformed in more than one way and still retain their idiomatic meanings. Syntactically flexible idioms were those that could be changed in at least three ways and still maintain their idiomatic interpretations. The following is an example of an idiom in each of its six transformations:

Verb changed to present participle

Mary was just letting off some steam and didn't mean to hurt anyone.

Adjective inserted

Mary let off some hidden steam when she yelled at her daughter.

Adverb inserted

Mary quickly let off some steam when she yelled at her daughter.

Voice changed to passive

Some steam was let off by Mary when she yelled at her daughter.

Action nominalized

The letting off of some steam by Mary helped her feel much better.

Particle moved

Mary let some steam off when she yelled at her daughter.

From the original list of 60 idioms, we saw 16 as syntactically frozen and 16 as syntactically flexible. To check the reliability of our intuitions, we compared our assessments of syntactic produc- 
tivity with the ratings given the subjects of Gibbs and Nayak (1987, Experiment 2). In that experiment, subjects were presented with idioms in different syntactic constructions and were asked to judge the degree of similarity between these sentences and sentences containing paraphrases of the original idioms' figurative meanings. The subjects' ratings were averaged across the different syntactic transformations and a syntactic frozenness continuum was established, ranging from idioms that were syntactically quite frozen to those that maintained their figurative meanings in a variety of syntactic forms. A comparison of our individual judgments of syntactic productivity with those of Gibbs and Nayak's subjects showed that all of the idioms we rated as syntactically limited came from the bottom quarter of Gibbs and Nayak's frozenness continuum, and all of the idioms we rated as syntactically productive came from the top third of the continuum. We interpreted these data as showing that people generally view the productive idioms used in the present study as being syntactically flexible and the frozen idioms as being syntactically frozen.

We assessed the familiarity of these stimuli in a separate rating study similar to that described in Experiment 1B, using 24 undergraduate students. Overall, these subjects were familiar with $92 \%$ of all the idioms, and an analysis of variance indicated no significant differences in their familiarity with the two types of idioms. A complete list of the syntactically productive and frozen idioms is presented in Appendix C. We should note that the idioms used as stimuli in this experiment were not identical to those used in Experiment $\mathbf{I B}$.

As described for the previous experiments, the idioms in each sentence either were left unchanged or were changed in one of three ways: (1) a synonym was substituted for the main verb, (2) a synonym was substituted for the main noun, or (3) synonyms were substituted for both the verb and the noun. The new words did not differ statistically from the original words in terms of their overall frequency, as determined by the ratings from Carroll et al. (1976).

Each of the sentences containing an original idiom (frozen or flexible) was paired with a short sentence containing a paraphrase of the original idiom's figurative meaning, taken directly from Boatner et al. (1975). The 32 idioms were used to form four sets of materials; each set contained 16 syntactically frozen idioms and 16 flexible ones. In each set, 4 had no changes, 4 had noun changes, 4 had verb changes, and 4 had both noun and verb changes. The different sets were appropriately counterbalanced as described for the previous experiments.

Procedure. The subjects were presented with a booklet containing the instructions and all the stimuli. They were asked to read each idiom-paraphrase pair and to judge, on a 7-point scale, the degree to which the expressions were similar in meaning. The task took approximately $20 \mathrm{~min}$ to complete.

\section{Results}

The mean similarity ratings for each type of idiomatic expression are presented in Table 4 . Note that lower ratings indicate phrases that do not retain their figurative interpretations when changed. The mean standard error for these ratings was \pm .25 .

A two-factor analysis of variance on these ratings showed that the subjects gave higher ratings to the syntactically flexible idioms than to the frozen ones $[F 1(1,35)$ $=49.9, p<.001 ; F 2(1,31)=30.3, p<.001$; $\left.\min F^{\prime}(1,60)=18.8, p<.001\right]$. Moreover, there were significant differences in the subjects' ratings of the various lexical changes $[F 1(3,105)=101.1, p<.001$; $F 2(3,93)=65.4, p<.001 ; \min F^{\prime}(3,184)=39.7$,
Table 4

Mean Ratings for Experiment 3

Idiom Type

\begin{tabular}{lccc}
\cline { 2 - 3 } Lexical Change & $\begin{array}{c}\text { Syntactically } \\
\text { Frozen }\end{array}$ & $\begin{array}{c}\text { Syntactically } \\
\text { Productive }\end{array}$ & Mean Rating \\
\hline None & 5.95 & 6.13 & 6.04 \\
Verb & 4.10 & 4.98 & 4.64 \\
Noun & 4.65 & 5.13 & 4.89 \\
Both & 2.93 & 3.88 & 3.39 \\
Mean Rating & 4.40 & 5.03 & \\
\hline
\end{tabular}

$p<.001]$. The interaction between type of idiom and type of change was also statistically reliable across both subjects and items $[F 1(3,105)=3.4, p<.025 ; F 2(3,93)$ $=3.0, p<.05]$, although not by $\min F^{\prime}\left[\min F^{\prime}(3,195)\right.$ $=1.6, p>.10]$.

Further comparisons on the individual means, using Newman-Keuls tests, indicated that the subjects gave higher ratings to both types of unchanged idioms than to any of the changed idioms ( $p<.05$ for all comparisons). For both the frozen and the flexible idioms, there were significant differences between those with the noun changed and those with both noun and verb changed ( $p<.05$ for each comparison). For both types of idiom, the differences between those with the verb changed and those with both noun and verb changed were also statistically reliable ( $p<.05$ for both comparisons). NewmanKeuls tests also indicated that for each type of lexical change, the subjects gave higher ratings to the syntactically productive idioms than to the syntactically frozen idioms $(p<.05$ for those with the verb changed and those with both noun and verb changed; $p<.10$ for those with the noun changed). These findings demonstrate that syntactically flexible idioms can be changed lexically more easily than idioms that are restricted in their syntactic productivity. Syntactically frozen idioms are limited to very specific lexical items and cannot undergo syntactic or lexical changes without losing their figurative meanings.

These data lend further support to the idiom decomposition hypothesis. Syntactically productive idioms have individual lexical items with meanings that contribute to the idiom's overall figurative meaning. Changing one semantic component disrupts the overall idiomatic meaning less for semantically productive idioms than for syntactically frozen idioms. Because the individual components' meanings play a small role in the overall figurative interpretations of syntactically frozen idioms, it makes less sense to change any of their individual lexical items.

\section{GENERAL DISCUSSION}

Our goal in the present study was to explain why some idioms are flexible in their lexical makeup. We investigated the hypothesis that differences in the lexical flexibility of idioms can be accounted for by examination of their internal semantics. An idiom that is perceived as be- 
ing decomposable (i.e., as having separate meaningful units) is more likely to be viewed as lexically flexible. Our expectation was that our subjects would find the changed idioms less acceptable than the original phrases. We predicted that changes in wording would disrupt the figurative interpretations of some idioms more than others.

In Experiment 1A we found that people can distinguish between normally decomposable, abnormally decomposable, and semantically nondecomposable idioms. The semantic composition of idioms is an independent property of these phrases, and people's intuitions about the decomposability of any idiom can be made apart from any determination of an idiom's lexical flexibility or syntactic productivity (cf. Gibbs \& Nayak, 1987).

Experiment 1B demonstrated that substitution of a synonym for either the verb or the noun was less damaging to the overall figurative meaning of a normally decomposable idiom than to that of a semantically nondecomposable idiom. Because the individual components of normally decomposable idioms contribute to their overall figurative meanings, it is often possible to make word substitutions as long as these changes maintain the same individual contribution to the phrase's figurative meaning as did the original word. On the other hand, the individual components of nondecomposable idioms do not contribute to their overall figurative meanings. It makes little sense, then, to change any of these idioms' individual components. Finally, abnormally decomposable idioms were found to be almost as lexically flexible as the normally decomposable phrases. A noun change was more disruptive to the figurative meaning of abnormally decomposable idioms than to that of normally decomposable idioms. In general, it appears that as long as a lexically altered component maintains the metaphoric relation between the individual component and its idiomatic referent (e.g., spill the beans, drop the beans), an abnormally decomposable idiom is viewed as somewhat lexically flexible.

The fact that abnormally decomposable idioms were found to be more flexible in their lexical makeup than were nondecomposable idioms highlights an important aspect of the idiom decomposition hypothesis. Semantic decomposability may be thought of as a semantic mapping between an idiom's individual components and their specific figurative referents. But this mapping need not be a literal one, with the literal meaning of an individual component (e.g., torch in the phrase carry a torch) corresponding to some literal referent in the real world (e.g., a strong feeling of affection). An idiom will be seen as analyzable or decomposable as long as there is some relation (concrete, abstract, or metaphorical) between its individual components and their figurative referents.

The results of Experiment 2 ruled out the alternative hypothesis that the lexical flexibility of idioms can be best explained in terms of their literal well-formedness. Literally well-formed idioms were not found to be more flexible in their lexical makeup than were ill-formed expressions. This finding adds further weight to the idea that the mapping between an idiom's individual components and their figurative referents need not be a strictly literal one. A brief examination of some of the normally decomposable idioms (e.g., pop the question) shows that these phrases need not have well-formed literal meanings in order to be decomposable or lexically flexible.

In Experiment 3 we assessed the lexical flexibility of idioms in phrases differing in their degree of syntactic productivity. Our expectation was that syntactically productive idioms should be more lexically flexible than frozen idioms precisely because productive idioms are more analyzable or decomposable, as demonstrated by Gibbs and Nayak (1987). The results of Experiment 3 were consistent with this prediction, in that changes in the lexical makeup of syntactically frozen idioms were more disruptive to their figurative meanings than were changes in the syntactically productive idioms. These findings, along with those of Gibbs and Nayak, suggest a common explanation for the lexical flexibility and syntactic productivity of idioms. Those idioms that are decomposable, with the meanings of the individual components contributing to the idioms' figurative interpretations, will be viewed as both syntactically versatile and lexically flexible.

One qualification to this conclusion concerns abnormally decomposable idioms that are somewhat flexible in their lexical makeup, although they are not syntactically productive (Gibbs \& Nayak, 1987, Experiment 1). It appears that people find it somewhat appropriate to change the lexical items within abnormally decomposable idioms as long as these substitutions maintain the same metaphorical relations to their figurative referents. However, it is still inappropriate to syntactically alter abnormally decomposable idioms, because it is unusual to focus on a particular component of an idiom when it has a metaphorical relation to its idiomatic referent. Thus, people find it difficult to focus on the object of an expression, such as John carried a torch for Jane, by moving that component into semantic focus through a passive operation (e.g., A torch was carried by John for Jane).

We have demonstrated that some idioms can be lexically altered without damage because their individual components contribute separately to the phrase's overall figurative interpretation. But what constrains the kinds of lexical changes that can be made without severely disrupting these phrases' idiomatic meanings? In the present experiments, we restricted the lexical changes made to the use of fairly close synonyms for the original verbs and nouns; we did not attempt to assess the effect of more radical changes on people's intuitions about the figurative meanings of idioms. Some lexical changes that are not synonyms may actually be less disruptive to an idiom's figurative meaning than a synonym substitution. For example, the phrase hit the hay loses some of its idiomatic meaning when a synonym is substituted for its noun (e.g., hit the straw), but maintains its idiomatic meaning quite well when the substitution is more different (e.g., hit the sack). In some cases, such as hit the sack, the lexically changed expression is eventually thought of as a separate idiom. Our point that such a lexical change works only 
with decomposable idioms still holds; in fact, restricting the lexical substitutions to synonyms probably results in an underestimation of differences in people's assumptions about the lexical flexibility of idioms.

One possible constraint on the kinds of lexical changes that can acceptably be made is the restriction that any new word must come from the same semantic field as the original lexical item and its figurative referent. A semantic field is a set of concepts and their lexical labels whose semantic decompositions all share at least one nuclear concept or feature (Miller, 1986; Miller \& Johnson-Laird, 1976). The similar figurative meanings given to hit the hay and hit the sack reflect the fact that hay and sack share similar features as well as sharing some features associated with their figurative referents (i.e., beds). For this reason, a person can say either hit the hay or hit the sack to mean "go to bed." Similarly, a speaker can say either button your lips or fasten your lips to mean "don't say anything."

We extend the significance of semantic fields beyond their utility in constraining the lexical changes that can be made to an idiom; we suggest that semantic fields are exactly what speakers make assumptions about in determining the analyzability of an idiom. It is precisely those idioms whose individual components come from the same semantic field as their idiomatic referents that are analyzable or decomposable. The individual components of idiomatic phrases such as kick the bucket or chew the fat are not in the same semantic fields as their figurative referents (i.e., "to die" or "to talk without purpose"), and consequently are quite frozen in their lexical makeup. Of course, there is some relationship between kick the bucket and "die" and chew the fat and "talk without purpose," but these connections are most often historical and/or arbitrary.

Our discussion of the lexical flexibility of idioms would be incomplete if we did not acknowledge the more creative side of lexical substitutions. It is possible to invent contexts in which even nondecomposable idioms can be lexically altered and still maintain their figurative meanings. A speaker could say "Last night Roberto and I masticated the gristle for hours." In this case, the speaker wishes to convey a specific figurative meaning (i.e., "Last night Roberto and I gabbed on for hours"), but also probably wants the listener to recognize the speaker's creativity in alluding to an old idiom (i.e., chew the fat). Writers, poets, and songwriters (Bob Dylan is a good example) often twist the lexical makeup of idioms to achieve certain poetic and/or stylistic effects. Although our results suggest that these innovations are most likely to be found in decomposable idioms, it may be possible to lexically change any idiom in a creative manner and still be understood if there is sufficient pragmatic context.

The most general implication of the present study concerns the traditional view that idioms are noncompositional. It is not likely that a motivated account of the lexical flexibility of idioms can be made unless it is assumed that idioms can be partially compositional. As is the case for the syntactic behavior of idioms (Gibbs \& Gonzales,
1985; Gibbs \& Nayak, 1987; Nunberg, 1978), the lexical makeup and the degree of lexical flexibility of idioms must be due to people's assumptions about the analyzability of idioms. This conclusion lends support to the idea that idioms do not form a unique class of linguistic items, perhaps as "dead"'metaphors, but share many of the compositional properties normally associated with more literal types of speech.

Our data showing the importance of semantic compositionality for the lexical flexibility of idioms also have direct implications for psycholinguistic theories of figurative language processing. Most models of language processing require that all idioms be viewed as noncompositional. Listeners and readers comprehend idioms through direct access of the figurative interpretation of any phrase that is stored along with the idiom in the mental lexicon. No compositional analysis of the individual words' meanings is necessary, supposedly, because the figurative meanings of idiomatic expressions are explicitly stipulated in the form of meaning postulates (see Weinreich, 1969).

However, the fact that idioms differ in their degree of semantic composition suggests that people may process decomposable and nondecomposable idioms differently. Semantically decomposable expressions may be analyzed in a compositional manner; the meaning of each component may be accessed and analyzed in a way similar to the way in which more literal speech is assumed to be processed. This does not necessarily imply that people must analyze an idiom's literal meaning (Gibbs, 1986), but they should recognize that certain words in decomposable idioms refer to parts of these idioms' overall figurative meanings. This kind of compositional parsing strategy is particularly useful because the individual parts of decomposable idioms can be rearranged into other syntactic constructions (e.g., John laid down the law can be changed to The law was laid down by John), or lexically altered (e.g., button your lips can be changed to fasten your lips) without disruption of the idioms' figurative meanings. People have little difficulty with decomposable idioms that have been syntactically transformed or lexically changed precisely because they can attach separate meanings to these phrases' individual components. Even though people appear to take longer overall to process unaltered decomposable idioms than to process unaltered nondecomposable idioms (Gibbs \& Gonzales, 1985), activation of the meanings of the individual parts of decomposable idioms permits greater flexibility in comprehending idioms in different forms and with varying lexical content.

Understanding of the figurative meanings of semantically nondecomposable idioms (e.g., kick the bucket) may be achieved through a different process. The nonliteral meaning of a nondecomposable idiom can be retrieved directly from the mental lexicon, just as the meaning of an individual word can be retrieved. Because nondecomposable idioms are seen in a small number of syntactic constructions, these phrases are more lexicalized, like long words, and can be easily accessed and understood (Gibbs 
\& Gonzales, 1985). A strict compositional analysis of semantically nondecomposable idioms would provide little information about the figurative meanings of these expressions. It is more appropriate to assume that nondecomposable idioms are understood through recovery of their figurative meanings, which have been directly stipulated as meaning postulates.

This characterization of how idioms are comprehended is somewhat speculative, and we are presently investigating the psychological validity of these hypotheses in our laboratory. We do not mean to suggest, at this point, that only two distinct processing mechanisms are used to comprehend all idiomatic expressions. Just as people's intuitions about the decomposability of any idiom can vary along some continuum of semantic decomposition, people may comprehend many idioms by using a combination of compositional and direct-access strategies, perhaps operating in parallel. In any event, our research on the lexical properties of idioms certainly suggests that idioms do not form a unique group of figurative language items, and that all idioms may not be understood in the same way.

\section{REFERENCES}

Becker, J. (1975). The phrasal lexicon. In B. Webber \& R. Schank (Eds.), Theoretical issues in natural language processing (pp. 70-73). Cambridge, MA: Association for Computational Linguistics.

Boatner, M., Gates, J., \& MakKaI, A. (1975). A dictionary of American idioms. New York: Barron's Educational Series.

Carroll, J., Davies, P., \& Richman, B. (1976). Word frequency book. New York: Houghton Mifflin.

CHомsкy, N. (1965). Aspects of the theory of syntax. Cambridge, MA: MIT Press.

Сномsкy, N. (1980). Rules and representations. New York: Columbia University Press.

ClARK, H. (1973). The language-as-fixed-effect fallacy: A critique of language studies in psychological research. Journal of Verbal Learning \& Verbal Behavior, 12, 335-359.

DowTY, D., WALL, R., \& PeTERS, S. (1980). Introduction to Montague semantics. Dordrecht, The Netherlands: Reidel.

FRASER, B. (1970). Idioms within a transformational grammar. Foundations of Language, 6, 22-42.

GASSER, M., \& DYER, M. (1986). Speak of the devil: Representing deictic and speech act knowledge in an integrated memory. In Proceedings of the Sixth Annual Meeting of the Cognitive Science Society (pp. 388398). Hillsdale, NJ: Erlbaum.

GiBBS, R. (1986). Skating on thin ice: Literal meaning and understanding idioms in conversation. Discourse Processes, 9, 17-30.

Gibbs, R., \& Gonzales, G. (1985). Syntactic frozenness in processing and remembering idioms. Cognition, 20, 243-259.

Gibbs, R., \& NaYAK, N. (in press). Psycholinguistic studies on the syntactic behavior of idioms. Cognitive Psychology.

Heringer, J. (1976). Idioms and lexicalization in English. In M. Shibatani (Ed.), Syntax and semantics: Vol. 6. The grammar of causative constructions (pp. 205-216). New York: Academic Press.

KATZ, J. (1973). Compositionality, idiomaticity, and lexical substitution. In S. Anderson \& P. Kiparsky (Eds.), A Festschrift for Morris Halle (pp. 357-376). New York: Holt, Rinehart \& Winston.

Kempson, R. (1977). Semantic theory. London: Cambridge University Press.

KUCERA, H., \& Francis, W. (1967). Computational analysis of presentday American English. Providence, RI: Brown University Press.

Miller, G. (1986). Dictionaries in the mind. Language \& Cognitive Processes, 1, 171-185.

Miller, G., JohNSON-LAIRD, P. (1976). Language and perception. Cambridge, MA: Harvard University Press.
Mueller, R., \&ibrs, R. (1987). Processing idioms with multiple meanings. Journal of Psycholinguistic Research, 16, 63-81.

NUNBERG, G. (1978). The pragmatics of reference. Bloomington: Indiana University Linguistics Club.

Weinreich, U. (1969). Problems in the analysis of idioms. In J. Puhvel (Ed.), Substance and structure of language (pp. 23-81). Los Angeles: University of California Press.

Wilensky, R., \& ARENS, Y. (1980). PHRAN: A knowledge-based approach to natural language analysis (Memorandum UCB/ERL M80/34). Berkeley: University of California at Berkeley, Electronics Research Laboratory.

Appendix A

Idioms Used in Experiments $1 \mathrm{~A}$ and 1B, With Lexical Changes (in Parentheses) Used in Experiment 1B

Normally Decomposable

pop the question (burst ... request)

miss the boat (avoid ... ship)

break the ice (crack ... frost)

play the market (compete ... fair)

get the picture (obtain ... idea)

lose one's grip (slip ... handle)

perish the thought (kill ... idea)

close the books (shut ... novels)

button one's lip (fasten ... mouth)

clear the air (clean ... breeze)

cool one's heel (chill ... feet)

open the door (clear ... gate)

Abnormally Decomposable

carry a torch (hold ... flashlight)

promise the moon (pledge ... star)

spill the beans (drop ... peas)

pass the buck (give ... dollar)

pull the plug (tug ... stopper)

bury the hatchet (sink ... axe)

hold the fort (carry ... stronghold)

grease the wheels (oil ... tires)

steal one's thunder (rob ... roar)

hit the sack (strike ... bag)

crack the whip (snap ... lash)

pay the fiddler (settle ... violin)

Nondecomposable

kick the bucket (punt ... pail)

chew the fat (gnaw ... lard)

raise the roof (lift ... ceiling)

make the scene (create ... picture)

give the sack (issue ... bag)

play the field (compete ... playground)

cook one's goose (broil ... bird)

shoot the breeze (fire ... wind)

pack a punch (stuff ... wallop)

give the bounce (issue ... spring)

speak one's mind (utter ... brain)

hit the sauce (strike ... gravy)

\section{Appendix B \\ Idioms and Lexical Changes Used in Experiment 2}

\section{Literally Well-Formed}

ring a bell (sound ... chime)

fall off the wagon (tumble ... truck)

paint the town (color ... city) 
Appendix B (continued)

hit the spot (strike ... place)

spill the beans (drop ... peas)

kick the bucket (punt ... pail)

miss the boat (avoid ... ship)

cook your goose (broil ... bird)

wear the pants (don ... trousers)

cool your heels (chill ... feet)

raise the roof (lift ... ceiling)

jump through the hoop (leap ... ring)

bat an eye (wink ... lash)

get the axe (obtain ... hatchet)

deliver the goods (release ... products)

rock the boat (sway ... ship)

shoot the breeze (fire ... wind)

lift a finger (raise ... hand)

pass the buck (give ... dollar)

carry the torch (hold ... light)

Literally Ill-Formed

fit the bill (accommodate ... check)

crack the joke (split ... pun)

pop the question (burst ... request)

swallow one's pride (ingest ... vanity)

make the scene (create ... picture)

jump down one's throat (leap ... larynx)

cramp your style (restrict ... manner)

drop a line (spill ... string)

nurse a grudge (foster .... anger)

pack a punch (stuff ... wallop)

lose your temper (forfeit ... composure)

eat your words (ingest ... utterance)

weigh one's words (measure ... utterance)

make the grade (create ... rank)

hold your peace (carry ... harmony)

boggle your mind (shake ... brain)

jump to a conclusion (leap ... inference)

take your time (grab ... minutes)

meet your eye (introduce ... lid)

play the field (compete ... playground)
Appendix C

Idioms and Lexical Changes Used in Experiment 3

Syntactically Productive

wear out his welcome (exhaust ... reception)

weigh one's words (measure ... speech)

turn one's stomach (twist ... tummy)

catch one's breath (seize ... wind)

walk on air (step ... sky)

jump to a conclusion (leap ... ending)

tip the scales (tilt ... balance)

hit the hay (strike ... straw)

breathe down your neck (exhale ...

collar)

bore to tears (tire ... crying)

waste your breath (squander ... air)

warm the bench (heat ... chair)

wash your hands of it (clean ... palms)

beat into your head (pound ... skull)

pull out of a hat (pick ... cap)

blow off some steam (exhale ... vapor)

Syntactically Frozen

head for the hills (advance ... mountain)

chew the fat (gnaw ... lard)

perish the thought (kill ... idea)

have a heart (own ... soul)

curl your hair (twist ... locks)

bet your boots (risk ... shoes)

at the drop of the hat (fall ... cap)

kick the bucket (punt ... bucket)

dead to the world (deceased ... earth)

go jump in a lake (leap ... pond)

ring the bell (clang ... chime)

say the word (speak ... expression)

bite the dust (nip ... dirt)

cut down the size (reduce ... volume)

shoot the breeze (fire ... wind)

make the scene (create ... picture)

(Manuscript received June 1, 1987;

revision accepted for publication March 6, 1988.) 